\title{
Synthetic Review of Organizational learning
}

\author{
Jamshid Ali Turi \\ Faculty of Industrial Management, \\ University Malaysia Pahang, Malaysia \\ Dr. Fatimah Binti Mahmud \\ Faculty of Industrial Management \\ University Malaysia Pahang, Malaysia \\ Hira Toheed \\ Department of Management Sciences \\ Bahria University Islamabad, Pakistan \\ Dr. Shahryar Sorooshian \\ Faculty of Industrial Management \\ University Malaysia Pahang, Malaysia
}

\begin{abstract}
This paper covers comprehensive literature analysis on organizational learning. Work on organizational learning was synthesised in systematic and chronological order. Cognitive, Social and Behavioural theories and factors in organizational context have been widely discussed to comprehend forgetting in organizational context. Moreover, historical and philosophical prospective of organization learning was also comprehended. All the theories, prevailing context and factors indicate, as evident from content analysis, have greater impact on organizational learning.
\end{abstract}

Keywords: Organizational Learning; Historical Prospective of Organizational Learning; Philosophical Organizational Learning; Theoretical Prospective of Organizational Learning; Learning Organization

\section{INTRODUCTION AND DEFINITION OF THE ORGANIZATIONAL LEARNING}

Organizational learning definition evolved with the passage of time. Comprehensive and agreed upon definition has not been presented yet. There are different sources and prospective of organizational learning, therefore, theorists found it difficult to define it in comprehensive way. It can be congenital, vicarious or can be from direct experiences. According, to organizational theory, organization learns at 1) Social- Psychological level, focusing on individual and interpersonal relation and it include Mayo's Hawthorn and Wb Max studies, 2) Structure level focuses on overall structure and departmental divisions, explained by Lawrence and Lorches in contingency theory and 3) Macro Level, focus on organization in response to environment and other organizations in Scott's analysis (Ahmad \& Lodhi, 2014).

The first formal definition was given by Argyris and Schon (1978) and called it as a process of organizational problem detection and correction. Daft and Weick (1984) called it as a relationship between organization's responses to environment. It was called as a process of improving action in light of better knowledge (Popova-Nowak \& Cseh, 2015), history based learning (Alhabeeb \& Rowley, 2017), innovation though sustainable actions (Schulz, 2001), expansion in organizational knowledge (Gilaninia, Rankouh, \& Gildeh, 2013), processing of 
information bringing behavioural changes among the employees (Balasubramanian, 2011), creation, disseminations and distribution of knowledge among employees and an increase in organizational capacities for better performance (King W. , 2009), minded inquiry, informed interpretations (Mangolte, 2000), change in organizational cognition and behaviour (Ang \& Joseph, 2011), continuous transforming for better performance and success (Agarwal \& Garg, 2012), complex interrelationship between people, their actions, symbols, and processes within the organization (Starbuck, 2017), process of gaining new insights, practices and experiences of organization for organization (Schnackenberg \& Tomlinson, 2014), organizational knowledge by its employees within its reference and context, multilevel process where individuals acquire and reflect knowledge, create, transfer, share and store it in organizational memory (Brockmeier, 2002). Similarly, some researcher focused on generational learning in organizational context, covering its internal environment covering tasks, process, values, cultures, peoples and tools and equipment and external environment include competitors, clients, government's policies and market's elements (Ashkanasy, 2016).

\section{ORIGIN OF THE ORGANIZATIONAL LEARNING}

Organizational learning research can be grouped into three majors prospective, i.e. learning due to internal preventive behaviour, learning due to change in organizational routine and learning for future prospective to enhance performance (Sampe, 2012). Due to these themes and their prospective, variety of disciplines contributed, in-sighted and influenced field of organizational learning (azma \& mostafapour, 2011; Choo, 2016). These disciplines range from economics, management science, organizational theory, strategic management, humanresources management, information science, knowledge engineering, artificial intelligence, philosophy, psychology, and educational science, to cognitive science (Singh \& Kumar, 2017; Gherardi \& Nicolini, 2001). Psychological sciences focused on the cognitive, behavioural and social development of the worker (Beauregard, Lemyre, \& Barrette, 2015), management sciences was concern with the accurate information gathering, processing and utilizations for strategic planning (Sampe, 2012), production management aimed to increase productivity due to enhancement in learning, sociology focused on social structure, bonding and leadership support for organizational learning and creating sound learning culture, a culture of trust and empowerment and natural sciences sough for the devising of technological tools for storing and sharing of organization learning (Sampe, 2012; Arumugam, Idris, \& Munusamy, 2015). Research approached to organizational learning should be a mixture of positivism, constructivism and phenomenology but mostly positivism is followed because of its nature and domain (Ahmad \& Lodhi, 2014).

The concept of organizational learning has enjoyed revived interest in both academia and the business world. Numerous definitions of organizational learning exist with little convergence or consensus on what is meant by the term, or its basic nature, has emerged. Because researchers tend to focus on different aspects of this complex phenomenon, results are generally neither comprehensive nor cumulative. Much of the empirical research on organizational learning has involved business and industry, not educational system systems. However, interest in examining organizational learning in educational system is increasing although educational system has typically structured learning only as an individual endeavour, envisioning educational system as enterprises where organizational learning takes place is not difficult. Educational system continue to face a steady stream of novel problems and ambitious demands most certainly will generate considerable pressure to learn new and more effective ways of doing business. The search to understand learning processes in educational system is particularly important given the growing conviction that learning system cannot simply adopt the actions of successful models but must develop their own paths of learning and transformation within their existing organizational cultures. 


\section{CONTEMPORARY RESEARCH IN THE ORGANIZATIONAL RESEARCH}

In 1950s, in reaction to the macroeconomists' stance, contemporary research gets started and this journey went till 1080s. New empirical research programs were funded and organizational learning came as diverse field of interconnected ideas (Schulz, 2001). Recently the notion of organizational learning has gained renaissance among both academics and practitioners to develop organizations. Early promoters of the concept found these ideas largely limited to the border of management thoughts and philosophies during the 1980s, but the 1990s saw a reawakening of interest (Apontea \& Zapata, 2013). Current interest can be seen and measured by the presences of so many research journals, who try to encompass organizational learning from different aspects and domains. Some of the renowned journals are Organization Science since (1991), Organizational Dynamics (1993), Accounting, Management and Information Technologies (1995), Journal of Organizational Change Management (1996). Similarly review articles are the evidences of acceptance and interests of the workers and organizations in the domain of organizational learning. Also, large volumes of articles in expert periodicals depicting the plan and administration of learning organizations confirm the prominence of organizational learning and information system specialists. New theories and hypotheses of information creation have turned out to be noticeable and formal knowledge. As we are moving into the twenty- first century, therefore, organizational learning guarantees to be an overwhelming point of view with impact on both authoritative research and administration hone (Alhabeeb \& Rowley, 2017).

\section{PROCESS OF THE ORGANIZATIONAL LEARNING}

The process of organizational learning starts with and from individuals. Individuals are the units, building block and the primary learning entity of any organization (Belle, 2016; Choo, 2016). They put together their individual capacities and capabilities in a synergetic and holistic manner to make the organization stable and stronger (A.Hart, Gilstrap, \& C.Bolino, 2016). Individual learns by observing, scanning and experiencing through their mental models and brought them under execution and control in organizational processes with specific context and references (Hernaus, Škerlavaj, \& Dimovski, 2014). In (Newk-Fo, Venable, \& Dell, 2012) Ridge (2005) and Thrum (2006) state that workers should be encouraged to share their tacit and explicit knowledge to knowledge repository and this central repository should be created by organizations. He further states that knowledge acquisition, storing, sharing and its institutionalization should be the basic process and asset of organization to groom and learnt exponentially. Through these sources tacit, explicit, codified information and skills can be transformed and transferred to organization. (H.Kim, 2013; Fiol \& Lyles, 1985).

Individual learning become organizational learning in four steps and depicted by Crossman, Lane and White Model (1999) of Organizational Learning Different versions of this model (extended) having been presented by different researchers in different settings (Castaneda \& Rios, 2008). Learning at individual level starts with intuitions and observations (Castaneda \& Rios, 2008). It is than interpreted within organizational context, integrate it organizational repository if it is found useful than it is made part of the organizational processes, policies and even objectives (Birmingham, 2015). Feed Forward Feedback plays their critical exploration and creation of new knowledge. Human knowledge becomes organizational and organizational knowledge become human in a cyclic way. And both contribute to one another by sharing their tacit knowledge, values and norms (Zamir \& Park, 2017). This process is best explained by Crossman, Lane and White Model (1999) of Organizational Learning in (Castaneda \& Rios, 2008). This model is also supported by structuration theory (Berends, Boersma, \& Weggeman, 2003). This model was updated and researched by other researcher's time to time. The model is given in figure no.1 


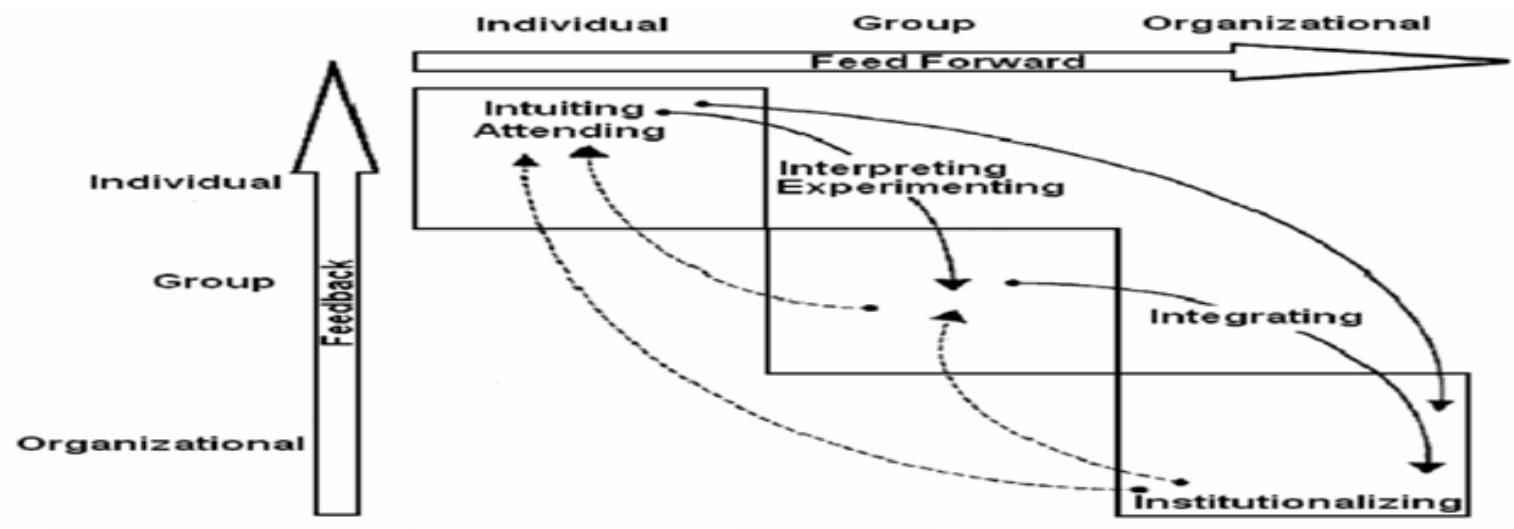

Figure 2.1 Extended model of organizational learning in practice, also named as 41 Model of OL Source (Lane and White Model (1999); Esther (2013)

\section{TYPES OF THE ORGANIZATIONAL LEARNING}

There are three main types of organizational learning, having widely discussed by different researchers (A.Hart, Gilstrap, \& C.Bolino, 2016). Single loop learning, which is also called adoptive learning, this concept was presented by Argyris and Donald Schon in the 1970s, focus on basic, overt, behavioural and action-based changes occur in organization to get expected and defined results and goals (VajihehSaadat \& ZeynabSaadat, 2016). It focuses on the change of the action and strategy to get the desired results (Kantamara \& Ractham, 2014). Double loop learning concept has also its origin in the writings of Argyris (1976), which is the process of spotting difficulties, identifying change on a justifiable valid foundation, choices, actions. It believes on the construction of new models and methods based on the new organizational insights and experiences (Belle, 2016). It also modifies the underlying norms, working conditions, policy and objective and get holistic understanding of the phenomenon and situations (Argyris, 1976; Fiol \& Lyles, 1985). Similarly Deutero Learning, which is also called higher level learning, is the learning about learning processes, methods and models. it focuses on the procedure of gaining knowledge using feedback mechanism, collaborative inquiry and reflection to structure models, techniques and policies in organizations (Belle, 2016). This term was first coined in 1942 by the Anglo-American anthropologist Gregory Bateson (1904-1980) and later modified by Argyris and Schon (1976). It tends to escape unequivocal directing and sorting out, particularly in its neurotic, twofold restricting structure, it doesn't really prompt to organizational or individual change (Argyris C. , 1974). This type of learning is discrete, subjective, contextual and cognizant. It is coordinated at organizational and individual change and occurs at planning and policy level.

\section{PHILOSOPHICAL PROSPECTIVE OF ORGANIZATIONAL LEARNING Epistemological Prospective of Organizational Learning}

Organizational epistemology has its roots in Nonaka's theory of knowledge creation, and Engstrom's expansive learning theory (Baek-Kyoo, 2010). It deals in creation, validation and applications of individual, group and organizational structured knowledge in organizational, social and sartorial context. It delete outdate knowledge and filled organizational repository with updated ones (Tennis, 2012). According to evolutionary epistemology, organizations must learn continuously new practices, model, methods and knowledge in the dynamic environment for their own survival (Aljuaid, Alzahrani, \& Islam, 2013). According to this philosophical point of view, organization should evaluate their existing knowledge for the better utilization of the resources, effectiveness and learning (Choo, 2016). 
Epistemology is the theory and validity of knowledge. It is a branch of philosophy mainly concerned with studying the source, prerequisites, characteristics, range, and factualness (precision, reliability, and efficiency) of learning. From the perspective of objectivism, organizational learning is an organizational action which is controllable and can be precisely predicted its process and outcome. They consider the organization as an entirely integrated system and emphasize holism and synergism with well-defined organizational structure designs, functions, and routines (Ahmed A. , 2008). In contrast, subjectivism-based organizational studies are founded based on social construction, symbolic interactions, hermeneutics, and postmodernism. These studies rely on texts, narratives, and dialogues (Van Buskirk \& McGrath, 1992) that result from the researcher's subjective view in engaging organizational learning. Moreover, the members of such organization can be given more authority, and instead of controlling them through bureaucratic means (Clegg, 1992), the organization can encourage pluralistic voices, views, and values (Hazen, 1993). The processoriented research strategy in organizational learning as studies pertaining to the process, method, nature, subject, and possible obstacles to such learning; this is a micro-level approach to organizational learning (Daud \& Kamsin, 2003). While the outcome-oriented research strategy analyses organizational learning based on the organization's capability and focused on the effect and outcome from the target-oriented viewpoint (Eisenberg, 2016).

\section{Ontological Prospective of Organizational Learning}

The branch of ontology in philosophy is concerned with human subjective and objective thoughts. Ontology confirms the essence of this subject and true intrinsic quality, and the perceptuality exists in all human phenomena and behaviour (Hodgkinson \& Healey, 2007). Ontology in western philosophy is characterized by two central viewpoints: the worldviews of being and becoming, which have also come to be known as, after further development, objectivism and subjectivism (Cook \& Yanow, 2012). In the following argument, we will comprehensively explain the meaning of an organization from the two key focal points of objectivism and subjectivism to pave the way for further organization-related analyses and discussions (Alhabeeb \& Rowley, 2017).

\section{Organizational Studies Based on Objectivism}

Objectivism, or the science of being, assumes that there exists a reality out there in this world and that we can comprehend and articulate the universal truths or at least the universal principles in existence. In terms of western philosophical views, objectivism primarily originated from realism; therefore, objectivism conveys the impression that the external transcendental world exists purely because of human consciousness (Chuang, 2009). Over the past century, organization theory in its contemporary form was predominantly built on mechanistic prospects. An organization operates by receiving inputs from the external world in the form of resources; it implements a transformation on these resources, and the resultant products or outputs are sent to other organizations. Such process ensures equilibrium and homeostasis in this pendulous setting (Blackman \& Henderson, 2013). The management of such an organization is based on scientific management, administrative principles, and bureaucracy-oriented classical management theory. It forms precise work design for procedural adoption, different courses of action, hierarchical separations of authority, written documentation, standardization, and other normalizing activity and competence evaluations (Blackman \& Henderson, 2013). Conversely, when the closed system viewpoint of organization's theory becomes an absurd factor in the face of rapid and massive changes in the surroundings (Hatch, 1997). Organization theory is also gradually transformed into its modern version, with further emphasis on respect for its environment. Due to this, not only does the organization theory encompass innumerable external factors but the organization is also obliged to allocate additional resources for coping with environmental factors during indefinite 
conditions, such as applying boundary spanning to buffer the uncertain conditions, and it became customary for the organization to adapt itself, through organizational evolution, to the changing surroundings. Thus, organization theory studies at this stage are known as modern organizational studies (Hatch, 1997; Serrat, 2009). Clegg (1992) state that researchers can manipulate objective perception using precise scientific calculations, to effectively represent the conversion of resources into products. Therefore, we have referred to organizational research based on the systems theory and objective measures approach as objectivism-based organizational research (Birmingham, 2015). The organizations should transform itself and its workers to cope with challenges and achieve the targeted objective and it can be done through continues organizational learning (Birmingham, 2015).

\section{Organizational Studies Based on Subjectivism}

Subjectivism is derived from the worldview of becoming and is also regarded as the science of becoming. It essentially focuses on transitory changes; therefore, subjectivism is not resultoriented but focuses on the process itself (Birmingham, 2015). Hatch (1997) believes that the symbolic-interpretive theory relies mainly on participants observations to obtain related narratives or texts, through which it can contribute to organizational studies conducted on either an individual or an ethnographic scale (Curado, 2004). The communal values and principles of the organization are intended to lay down the standards for guiding members within the organization as well as external individuals, to facilitate more profound interactions. To sustain intrinsic stability under such circumstances, organizations have progressively developed principles of cooperation and coordination focusing on to strengthen the basic structure, routines, and system). Similarly, Postmodernist studies have responded to the complexities and bulkiness of organizations by reassessing the popular values and structures of past organizations; such studies have suggested a return to a comparatively smaller and, in turn, a more controllable organization.

\section{Sociological Prospective of Organizational Learning}

It is well known fact that learning does not take place in isolation. It needs environment, stimuli and participation of individuals (Curado, 2004). According to the constructivist perspective, what is learned is profoundly connected to the conditions in which it is learned. Therefore, knowledge should not be isolated from practice and the context. Organizations are involved in a set of practices in an organized way, where they exchange and stimulate different practices and processes, which provides foundations for organizational learning (Gherardi \& Nicolini, 2001). Reflexivity concept also second the sociological prospective of organizational learning with the stance that learning occurs due to repeated interruptions. Knowledge and practices are criticized time and again which leads to the productions of contextual settings and institutionalize the contents for the expected outcomes in the organizations and revise the practices, methods and theories in use (Hilden \& Tikkamäki, 2013). Critical analysis, rejection and then acceptance, according to reflexivity work as a fuel for organizational learning (Hilden \& Tikkamäki, 2013).

\section{Cognitive learning theories \\ THEORETICAL PROSPECTIVE OF ORGANIZATIONAL LEARNING}

Organizational cognition is a discipline which contributes to improve the computational capacity of the organization along with its ability for knowledge management. It can be also developed artificially with the active interaction of human computer/ machine interaction to change and improve based upon the organizational goals (Hodgkinson \& Healey, 2007). There are different cognitive theories considers organizations as a learning entity and an extended individual (Göhlich, 2016; Goldin, 2014). Some theorists called the cognitive system of organizations as mental models (Gaine, 2014), cognitive maps (Alemanno, 2014), collective 
memory, cognitive memories systems (Mead, 2013). Similarly, Daft and Weick (1984) asserts that individual's knowledge is made cohesive with organization when they share their learning and experiences with management which are assessed, reshaped and distributed among workers (Gilaninia, Rankouh, \& Gildeh, 2013). Moreover, researchers suggest that these cognitive system form the basis of organizations' information processing mechanisms, enabling the organization to detect environmental events, opportunities and threats. Interpretation of this environmental data is a crucial stage occurring immediately before organizational learning and action (Huang, 2016). Interpretations of environmental information are done in organizational references and context because what is required is kept otherwise discarded (Alhabeeb \& Rowley, 2017). While Daft and Weick (1984) point to the need and necessity for organizations to develop and design their interpretation system (Fiol \& A, 1985; Goh \& Reyan, 2002; Kim, 1993).

According to learning theories not only information but experiences also leave greater impact on learning in organizations. These learning converts abstract ideas to practical experiences (Agarwal \& Garg, 2012; House of Commons, 2009). Kolb (1973) sates that learning takes place progressively, and moves from concrete experience to reflective observation, then abstract conceptualization, and finally active experimentation. This perspective suggests an active interconnection between cognition and action (Caple \& Martin, 1994). By developing learning typology based on individual preferences, Kim (1993) believes that experiential learning theory and rational calculation model of organizational choice explains the process of assimilation and accommodation (Wang \& Ellinger, 2014). Computational cognitive theory takes and support all social, cognitive and behavioural factors for the learning development at individual and organizational level (Sun, 2012).

\section{Behavioural learning theories}

Behavioural learning focuses on objectively observable behaviour of the learning entity (Choo, 2016). This happens because of a learning process called conditioning, which is based on a stimulus triggering a response (Gaine, 2014). For Weick (1991), "the defining property of learning is the combination of same stimulus and different response". Similarly, Cryert and March (1963) see organizational learning as involving adaptation to the environment. For them, organizational learning occurs when an organization, in response to "an external source of disturbance or shock", selects behaviours that lead the organization "to a preferred state" (Kolb, Boyatzis, \& Mainemelis, 1999; Eisenberg, 2016). All single, Double-loop and Deutero learning are not independent from its consequences and all of them are triggered by stimulus, questioning and reasoning. They link changes in the level of behavioural and cognitive development through social networking between the two determines the type of learning that takes place. Their work perceives learning as an adaptation process and distinguish between lower-level and higher-level learning, the former being merely repetition of past behaviour and behavioural adaptation to consequences of past behaviour and involving association building between behaviour and outcome (Hieronymi, 2013). This can also be described as pathdependency (Nelson \& Winter, 1982), meaning that organizations base their future behaviour on cumulative learning that worked in the past, which is like the idea of positive reinforcement in behavioural conditioning. it includes questioning the consequences of behaviour and seeking a more profound understanding of the causation of organizational processes (PopovaNowak \& Cseh, 2015).

\section{Social Learning Theories}

There are many cited social learning theories in organizational context. Relational learning theory is based on the concept of sharing, dissemination, distribution and negotiation taking place at micro-level, worker level (Bustinza, Molina, \& Arias-Aranda, 2010; Beauregard, 
Lemyre, \& Barrette, 2015). Similarly Experiential Learning Theory (ELT) was presented by Kolb in 1984 and has its roots in Psychology, Philosophy, and physiology and has major impacts and influences on organizational learning and organizational development (Leavitt, 2011). It states that learning is a process and it occurs in the best way when a learner is exposed to diverse processes and experience, through which it underpasses and creation, recreation and transformation of experiences and learning take place both at individual and organizational learning (Beauregard, Lemyre, \& Barrette, 2015). Adoptive and Generative Organizational Learning Theory believes in the construction and development of the shared vision and intelligence at worker, team and organizational level (Chiva, 2011). Assimilation Theory of Organizational Learning focuses on action and performance based learning (Educator's Voice, 2012). Moreover, New Institutional Theory of Organizational Learning presented by John Meyer and colleagues such as Brian Rowan in 1977 and Richard Scott in 1983, and by Lynne Zucker in 1977, postulates that with the passage of time, organizations react and adjust to internal and external demands and reflects changes in their cognitive, normative (Social and cultural) and regulatory (Behavioural) domains (Meyer \& Höllerer, 2014; Palthe, 2014). New-institutional theory also supports 4I framework arguments for organizational learning, where the learning process get starts from the individual and later get institutionalized in the organizational repository (Veisi, 2010). Socio-Technical Theory of Organizational Learning basic premise and philosophy is that any work, enterprise and organization is the combination of both social and technical (soft and hard) components and they are open to environment and both effects each other in a bidirectional way (Appelbaum, 2000). It provides social support, solves complexities and assures availability of the information to the workers. Main promise of this theory is the participatory approach, interaction and involvement of the workers with information technology which guides and promotes learning (Sawyer \& Jarrahi, 2013).

\section{HISTORY PROSPECTIVE OF THE ORGANIZATIONAL LEARNING}

Organizational learning was researched by different renowned scholars from different prospective. Their work is cited in chronological order in the following section.

\section{Argyris and Schon}

Argyris and Schon have tied the concept of organizational learning to Dewey's (1933/1960) conception of inquiry in which thought and action are viewed as intertwined to move from a state of doubt or confusion to a resolution of doubt. They presented the theories-ofaction/theories-in-use and single- and double-loop learning (Huysman, 2009; Ahmad \& Lodhi, 2014). Theories of action focus on actions, strategies (Sampe, 2012). These theories take two distinct forms. Espoused theories of action are those provided to explain or justify a pattern of activity or a way of doing things (Chuang, 2009). Theories-in-use are the theories of action that are implicit in the way things are done.

Learning involves changes in these theories either by refining them single-loop learning or by questioning underlying assumptions, norms, or strategies so that new theories-in-use emerge double-loop learning. Similarly, Double-loop learning changes organizational frames of reference (Palthe, 2014).

\section{Daft and Weick}

The second view of organizations as interpretation systems highlights the idea that organizational members try to interpret what they have done, define what they have learned, and solve the problem of what to do next. Daft and Weick (1984) maintain that although organizations do not have mechanisms separate from individuals to set goals, process information, or perceive the environment, the organizational interpretation process is more 
than the sum of what occurs individually. A distinctive feature of organizational interpretation is the sharing of data, perceptions, and puzzling developments that allows groups to converge on an approximate interpretation (Belle, 2016).

\section{Fiol and Lyles}

Fiol and Lyles (1985) state that major theorists (including Daft and Weick) generally agree that although individual learning is important to organizations, but organizational learning is not simply the sum of each member's learning. Fiol and Lyles suggested that the literature discussed that social, behavioural and cognitive changes by an organization as constituting learning. Social and Behavioural changes concerns actual responses, structures and/or actions. Cognitive change, by contrast, concerns new and shared understandings or "conceptual maps" of organizational members (Daud \& Kamsin, 2003).

Based upon these changes, Fiol and Lyles (1985) proposed a distinction between organizational adaptation and organizational learning. Organizational adaptation involves behavioural and social changes separate from cognitive changes; that is, "the ability to make incremental adjustments because of environmental, goal, policy, or other changes". This concept is like the concept of single-loop learning. Organizational learning, on the other hand, involves not only behavioural changes but also cognitive changes new insights, understandings, cognitive maps, and associations between past actions, their effectiveness (in terms of desired outcomes) and future actions. This concept is associated with higher-level learning and double-loop learning (Kantamara \& Ractham, 2014).

\section{Levitt and March}

Finally, theorists Levitt and March (1988), in their analysis of organizational learning placed greater emphasis on routinized behaviours than on organizational inquiry and interpretation. They described organizational learning as routine-based, history-dependent, and targetoriented (Gaine, 2014). They also include the structure of beliefs, frameworks, paradigms, cultures, and knowledge that bolsters, elaborates, and contradicts the formal routines. Routines are transmitted among organizational members through a variety of means including socialization, education, professionalization, imitation, and personnel movement.

Levitt and March (1988) viewed organizational interpretation as a challenging task because it involves making difficult judgments about cause and effect based on limited information within a highly complex system (Stene, et al., 2016; Zamir \& Park, 2017). They thus downplayed organizational interpretation, cautioning that it can be tainted by the ambiguity of success and/or by the organization's frames of reference that limit how history is seen and interpreted. Success itself can be a barrier to organizational learning because successful organizations may fall into "complacency traps" where they rely almost solely on the lessons of past achievements to guide future action captured this phenomenon in examining change processes in Educational system. He observed that in most educational change processes, there is an "implementation dip" when things get worse before they get better. Almost anyone who has switched from using a typewriter to a computer can attest to this. They are likely to maintain that a temporary loss of competence and/or comfort was, at least initially, a barrier to change (Belle, 2016).

Finally, Levitt and March (1988) caution that superstitious learning can occur when incorrect interpretations about the connections between actions and outcomes persist in their association (Ahmad \& Lodhi, 2014). 


\section{CONCLUSION}

In considering the different views of organizational learning highlighted above, several important points of agreement emerged among the different perspectives. There is considerable agreement among the above-mentioned theorists that organizational learning involves different aspects of learning (individual, group, organization), that it requires inquiry, that it results in shared understandings, and that it implies behavioral, social and cognitive change. For example, Argyris and Schon (1996) viewed organizational learning as the sharing of assumptions developed through individual and collective inquiry, whereas Levitt and March (1988) and Olsen (1976) emphasized organizational learning as adaptation to changes in the environment by adjusting strategies and structures including procedures and routines. Similarly, organizational cognitive and socio-technical theories considered organizational learning as multi-phase process, which involve cognitive, social and behavioral domains. Although there is considerable debate whether organizational learning is adaptive behavior or whether lessons learned are embodied in shared cognitive maps that guide behavior, many theorists agree that learning involving behavioral, social and cognitive change.

\section{Reference}

I. V. Popova-Nowak and M. Cseh, "The Meaning of Organizational Learning: A Meta-Paradigm Perspective," Human Resource Development Review, Vol. 14(3) , p. 299-331, 2015.

A. Alhabeeb and J. Rowley, "Critical success factors for eLearning in Saudi Arabian universities," International Journal of Educational Management, Vol. 31 Issue: 2, pp. 131-147, 2017.

M. Schulz, "Organizational Learning," University of Washington, Washington, 2001.

S. Gilaninia, M. A. A. Rankouh and M. A. P. Gildeh, "OVERVIEW ON THE IMPORTANCE OF ORGANIZATIONAL LEARNING AND LEARNING ORGANIZATION," Journal of Research and Development Vol. 1, No.2, pp. 44-50, 2013.

Balasubramanian, "Organizational Learning and Information Systems," Rutgers University, Newyork, 2011.

W. King, "Knowledge Management and Organizational Learning," Annals of Information Systems 4, pp. 3-15, 2009.

P. A. Mangolte, "Organisational Learning and the Organisational Link : The Problem of Conflict, Political Equilibrium and Truce," European Journal of Economic and Social Systems, 14 (2), pp. 173-190, 2000.

S. Ang and D. Joseph, "Organizational Learning and Learning Organizations: Trigger Events, Processes, and Structures," Academy of Management Review , pp. 213-236, 2011.

S. Agarwal and A. Garg, "The Importance of Communication within Organizations: A Research on Two Hotels in Uttarakhand," Journal of Business and Management (IOSRJBM), pp. 40-49, 2012.

W. H. Starbuck, "Organizational learning and unlearning," The Learning Organization, Vol.24 Issue: 1, pp. 30-38, 2017.

A. K. Schnackenberg and E. C. Tomlinson, "A New Perspective on Managing Trust in Organization-Stakeholder Relationships," Organizational Transparency, 2014.

J. Brockmeier, "Remembering and Forgetting: Narrative as Cultural Memory," Culture \& Psychology,Vol. 8(1): 1543, p. $15-43,2002$.

N. M. Ashkanasy, "Why we need theory in the organization sciences," Journal of Organizational Behavior, 2016.

F. Sampe, Th inflence of organizational learning on performance in Indonesian SMEs, NSW: Southern Cross University, 2012.

F. azma and M. a. mostafapour, "Identify Knowledge management And Organizational Learning Indicators and its Relation With Creativity," Procedia - Social and Behavioral Sciences Volume 30, pp. 2249-2252, 2011.

C. W. Choo, "The Inquiring Organization: How Organizations Acquire Knowledge and Seek Information," in Social Epistemology and Organizational Learning, Oxford, Oxford , 2016.

Singh and Kumar, "A Study on Infrastructure and Organizational Learning: Retahinking Knowledge Perfromance," International Journal of Social Sciences, Volume 3 Issue 2, pp. 61-77, 2017.

S. Gherardi and D. Nicolini, "The sociological foundations of organizational learning," Research Gate, pp. 27-60, 2001. 
N. Beauregard, L. Lemyre and J. Barrette, "The Domains of Organizational Learning Practices: An Agency-Structure Perspective," Societies, pp. 713-734, 2015.

T. Arumugam, K. Idris and K. Munusamy, "Conceptualizing Organizational Learning System Model and Innovativeness," International Journal of Business and Social Science, pp. 155-166, 2015.

N. Ahmad and S. Lodhi, Role of Knowledge management on organizational performance, Abbottabad: COMSATS University, 2014.

S. P. D. Apontea and D. I. C. Zapata, "A model of organizational learning in practice," Estudios Gerenciales 29, pp. 439-444, 2013.

S. Belle, "Organizational learning? Look again," The Learning Organization, pp. 332 - 341, 2016.

T. A.Hart, J. B. Gilstrap and M. C.Bolino, "Organizational citizenship behavior and the enhancement of absorptive capacity," Journal of Business Research Volume 69, Issue 10, pp. 3981-3988, 2016.

T. Hernaus, M. Škerlavaj and V. Dimovski, "Relationship between OrganizationalLearnign and Performance: A Case of Criatia," 2014.

W. Newk-Fo, H. T. J. Venable and P. Dell, "How Organisations Know What They Know: A Survey of Knowledge Identification Methods among Australian Organisations," in 23rd Australasian Conference on Information Systems, Australia , 2012.

D. H.Kim, "The link between Individual and organizational learning," learning organization, pp. 12-23, 2013.

M. Fiol and M. A. Lyles, "Organizational Learning," The Academy of Management Review, Vol. 10, No. 4, pp. 803-813, 1985.

D. I. Castaneda and M. F. Rios, "From Individual Learning to Organizational Learning," The Electronic Journal of Knowledge Management, pp. 363 - 372, 2008.

U. o. Birmingham, "Learning theories, stages and styles," University of Birmingham , Birmingham, 2015.

Z. B. Zamir and I. Park, "The Impact of Knowledge Capture and Knowledge Sharing on Employees' Outcomes," in global, international, and cross-cultural issues in IS (SIGCCRIS), 2017.

H. Berends, K. Boersma and M. Weggeman, "The structuration of organizational learning," Human Relations Volume 56(9), p. 1035-1056, 2003.

VajihehSaadat and ZeynabSaadat, "Organizational Learning as a Key Role of Organizational Success," Procedia Social and Behavioral Sciences Volume 230, Issue 12 , pp. 219-225, 2016.

P. Kantamara and V. V. Ractham, "SINGLE-LOOP vs. DOUBLE-LOOP LEARNING: AN OBSTACLE OR A SUCCESS FACTOR FOR ORGANIZATIONAL LEARNING," International Journal of Education and Research , pp. 55-63, 2014.

Argyris, "Single-Loop and Double-Loop Models in Research on Decision Making," Administrative Science Quarterly, pp. 363-375, 1976.

C. Argyris, "Single-Loop and Double-Loop Models in Research on Decision Making," Administrative Science Quarterly, Vol. 21, No. 3, pp. 363-375, 1974.

Baek-Kyoo, "Organizational commitment for knowledge workers: The roles of perceived organizational learning culture, leader-member exchange quality, and turnover intention," Human Resource Development Quarterly, 2010.

J. T. Tennis, "Epistemology, Theory, and Methodology in Knowledge Organization: Toward a Classification, Metatheory, and Research Framework," Knowledge Organization, pp. 102-112, 2012.

N. M. F. Aljuaid, M. A. R. Alzahrani and A. Islam, "Assessing Mobile Learning Readiness in Saudi Arabia Higher Education: An Empirical Study," The Malaysian Online Journal of Educational Technology, pp. 44-67, 2013.

A. Ahmed, "Ontological, Epistemological and Methodological Assumptions:Qualitative Versus Quantitative," University of Exeter, UK, 2008.

N. R. Daud and A. Kamsin, "The Study of Learning Organisations in Malaysia," University of Malaya, Malaysia, 2003.

D. T. Eisenberg, "The Restorative Workplace: An Organizational Learning Approach to Discrimination," University of Maryland, 2016.

G. P. Hodgkinson and M. P. Healey, "Cognition in Organizations," Annual Review of Psychology, pp. 387-417, 2007.

N. Cook and D. Yanow, "Culture and Organizational Learning," Journal of Management Inquiry, pp. 355-372, 2012. 
H. H.-C. Chuang, "Psychological Safety and Group Learning: Cycle-Time Reduction for Collaborative Product Development," Texas A\&M University, Texas , 2009.

D. Blackman and S. Henderson, "Does A Learning Organisation Facilitate Knowledge Acquisition And Transfer," 2013.

C. Curado, "Organizational Learning And Organizational Design," Technical University of Lisbon, Portugal , 2004.

S. Hilden and K. Tikkamäki, "Reflective Practice as a Fuel for Organizational Learning," The Administrative Sciences, pp. 76-95, 2013.

M. Göhlich, "Theories of Organizational Learning as resources of Organizational Education," Springer Fachmedien Wiesbaden, pp. 11-22, 2016.

C. Goldin, "Human Capital," Harvard University, 2014.

B. R. Gaine, "Social and Cognitive Processes in Knowledge Acquisition," Knowledge Science Institute, Canada, 2014.

S. P. Alemanno, "Risques organisationnels et anticipation," Communication et organisation, vol 45, pp. 1-15, 2014.

A. Mead, IDENTITY AND SENTIENT EMOTIONS AT WORK, Australia: Macquarie University, 2013.

R. M. Huang, "Organizational Learning: The Path to Growth," Scripps Senior Thesis, pp. 12-41, 2016.

L. c. Fiol and M. A, "Organizational Learning," Academy of Managemenl Revien. 1985. Vol. 10. No. 4. 803-813, pp. 803-813, 1985.

S. Goh and P. Reyan, "Learning Capabilitiy, organzational factors and Firm Performance," in Third European Confrence on Organizational knowledge, learning and capacities, Greece, 2002.

D. H. Kim, "The Link between Individual and Organizational Learning," MIT salon Management Review , UK, 1993.

House of Commons, "Engineering: turning ideas into Realities," House of Commons , London, 2009.

J. Caple and P. Martin, "Reflections of Two Pragmatists A Critique of Honey and Mumford's Learning Styles," Industrial and Commercial Training, Vol. 26 No. 1, pp. 16-20, 1994.

Y.-L. Wang and A. D. Ellinger, "Organizational Learning and Innovation Performance: A Review of the Literature and the Development of a Conceptual Framework," University of Illinois at Urbana-Champaign , 2014.

R. Sun, "Introduction to Computational Cognitive Modeling," Inaternational journal of Computational Sciences, pp. 11-34, 2012.

D. A. Kolb, R. E. Boyatzis and C. Mainemelis, "Experiential Learning Theory: Previous Research and New Directions," Department of Organizational Behavior Case Western Reserve University, Cleveland, 1999.

A. Hieronymi, "Understanding Systems Science: A Visual and Integrative Approach," Systems Research and Behavioral Science, p. 580-595, 2013.

O. F. Bustinza, L. M. Molina and D. Arias-Aranda, "Organizational learning and performance: Relationship between the dynamic and the operational capabilities of the firm," African Journal of Business Management Vol. 4(18), pp. 4067-4078, 2010.

C. Leavitt, "A Comparative Analysis of Three Unique Theories of Organizational Learning," University of wales, San Diego, 2011.

R. Chiva, "A FRAMEWORK FOR ORGANIZATIONAL LEARNING TYPES: GENERATIVE, ADAPTIVE AND ZERO LEARNING," University Jaume I 12071 Castellón Spain, Spain, 2011.

Educator's Voice, "Inquiry-Based Learning: Preparing Young Learners for the Demands of the 21st Century," Educator's Voice, 2012.

R. E. Meyer and M. A. Höllerer, "Does Institutional Theory Need Redirecting?," Journal of Management Studies, pp. 1221-1233, 2014.

J. Palthe, "Regulative, Normative, and Cognitive Elements of Organizations: Implications for Managing Change," Management and Organizational Studies, pp. 59-68, 2014.

H. Veisi, "Organizational Learning in the Higher Education Institutions (A Case Study of Agricultural and Natural Recourses Campus of University of Tehran)," International Online Journal of Educational Sciences, pp. 21-36, 2010.

S. H. Appelbaum, "Socio-technical systems theory: an intervention strategy for organizational development," Concordia University , Canada, 2000. 
Turi, J. A., Mahmud, F. B., Toheed, H., \& Sorooshian, S. (2019). Synthetic Review of Organizational learning. Advances in Social Sciences Research Journal, 6(4) 168-180.

S. Sawyer and M. H. Jarrahi, "Sociotechnical approaches to the study of Information Systems," Syracuse University, USA, 2013.

G. Tovstiga, S. Odenthal and S. Goerner, "Sense-Makingand learning in Complex Organizations: The String Quatertet Revisited," in The Fifth European Conference on Organizational Knowledge, Learning and Capabilities Innsbruck, Austria, 2004. 